\title{
HIV Testing and Counseling Among Female Sex Workers: A Systematic Literature Review
}

\author{
Anna $\operatorname{Tokar}^{1}\left[\right.$ D . Jacqueline E. W. Broerse ${ }^{2}$. James Blanchard ${ }^{3} \cdot$ Maria Roura $^{1,4}$
}

Published online: 20 February 2018

(c) The Author(s) 2018. This article is an open access publication

\begin{abstract}
HIV testing uptake continues to be low among Female Sex Workers (FSWs). We synthesizes evidence on barriers and facilitators to HIV testing among FSW as well as frequencies of testing, willingness to test, and return rates to collect results. We systematically searched the MEDLINE/PubMed, EMBASE, SCOPUS databases for articles published in English between January 2000 and November 2017. Out of 5036 references screened, we retained 36 papers. The two barriers to HIV testing most commonly reported were financial and time costs—including low income, transportation costs, time constraints, and formal/informal payments - as well as the stigma and discrimination ascribed to HIV positive people and sex workers. Social support facilitated testing with consistently higher uptake amongst married FSWs and women who were encouraged to test by peers and managers. The consistent finding that social support facilitated HIV testing calls for its inclusion into current HIV testing strategies addressed at FSW.
\end{abstract}

Keywords HIV diagnosis $\cdot$ HIV testing $\cdot$ Female sex workers $($ FSWs) $\cdot$ Systematic review

\section{Resumen}

La aceptación a realizar las pruebas de VIH continúa siendo baja entre las Mujeres Trabajadoras Sexuales (MTS). Nosotros sintetizamos evidencias sobre las barreras y las facilidades para realizar las pruebas de VIH entre las MTS, así como sobre las frecuencias de la prueba, voluntad de evaluar y tasa de retorno para recoger los resultados. Se realizaron búsquedas sistemáticas en las bases de datos MEDLINE/PubMed, EMBASE,SCOPUS para artículos publicados en inglés entre enero del 2000 y noviembre de 2017. De 5036 referencias examinadas, elegimos 36 artículos. Las dos barreras más comunes para las pruebas de VIH fueron los costos financieros y de tiempo, incluyendo: bajos ingresos, costos de transporte, limitaciones de tiempo y pagos formales/informales, así como el estigma y la discriminación atribuidos a las personas y trabajadoras sexuales seropositivas. El apoyo social facilitó las pruebas de VIH con una mayor aceptación entre las MTS casadas y las mujeres a quienes sus compañeros y gerentes les animaron a realizarlas. El hallazgo consistente en que el apoyo social facilitó las pruebas de VIH requiere su inclusión en las estrategias actuales de pruebas de VIH realizadas en MTS.

Anna Tokar

anna.tokar@isglobal.org

Jacqueline E. W. Broerse

j.e.w.broerse@vu.nl

James Blanchard

blanchard@cc.umanitoba.ca

Maria Roura

maria.roura@ul.ie
2 Athena Institute, Faculty of Science, Vrije Universiteit Amsterdam, Amsterdam, The Netherlands

3 Department of Community Health Sciences, Manitoba University, Manitoba, Canada

4 Public and Patient Involvement Research Unit, Graduate Entry Medical School, University of Limerick, Limerick, Ireland

1 ISGlobal, Barcelona Institute for Global Health, University of Barcelona, Hospital Clínic - Universitat de Barcelona, Rosselló, 132, 08036 Barcelona, Spain 


\section{Introduction}

Worldwide, early HIV testing is a public health priority especially among key populations such as female sex workers (FSWs) [1-3]: out of the estimated 33 million people living with HIV in the world, 19 million do not know their status [1]. Early HIV diagnosis has gained significant attention within key global health institutions, including the Joint United Nations Program on HIV/AIDS (UNAIDS) and the recently established 90-90-90 targets [4]. It is proposed that by $2020,90 \%$ of all people living with HIV should know their HIV status, $90 \%$ of all people with diagnosed HIV should receive sustained antiretroviral treatment, and $90 \%$ of all people receiving antiretroviral treatment should reach viral suppression [4]. Historically, HIV prevention efforts focused on key populations, including sex workers, as an effective approach to reduce HIV transmission, particularly in the early phase of the epidemic [5].

Several systematic reviews have examined HIV prevalence [6-8] and effectiveness of different HIV prevention interventions for SWs [9-12]. Shahmanesh et al. presented evidence for the efficacy of multi-component interventions, and/or structural interventions [9]. A Cochrane review of behavioral interventions concluded that, compared with standard care or no intervention, behavioral interventions are effective in reducing HIV and the incidence of STIs amongst FSWs [10]. A systematic review of community empowerment interventions in low- and middle-income countries demonstrated significant protective combined effect for HIV infection (prevalence), STIs such as gonorrhea and chlamydia, and increase of consistent condom use with all clients [12]. A systematic review of community empowerment interventions in generalized and concentrated epidemics has shown their positive impact on HIV prevalence, estimated number of averted infections among SWs and adult population, and expanded coverage of ART [11]. These previous studies did not systematically assess HIV testing approaches, but rather examined the combined effect of a variety of prevention activities. Thus, they failed to address unique determinants of different HIV testing approaches.

HIV testing activities among sex workers were assessed in only two papers including a meta-analysis of communitybased approaches [13], and a study of barriers to HIV testing in Europe [14]. According to these studies, communitybased HIV testing leads to higher HIV testing rates than facility-based testing, and the most common barriers to HIV testing are low-risk perception, fear and worries, poor accessibility to healthcare services, health providers' reluctance to offer the test, and scarcity of financial and human resources. Still, neither of those studies focused on FSWs nor systematically reviewed unique facilitators and barriers to HIV testing faced by this group. The present review compiles existing evidence on HIV testing among FSWs in order to better meet the needs of this group while implementing the first target of the 90-90-90 strategy. Our specific objectives are: (1) to summarize data on key barriers and facilitators to HIV testing among FSWs, and (2) to systematically review frequencies of testing, willingness to test, and return rates to collect HIV test results in this population.

\section{Methods}

We applied a free text strategy and MeSH terms to systematically scan the electronic databases MEDLINE/PubMed using the platform OVID, and EMBASE and SCOPUS. We employed a combination of terms that covered the concepts 'HIV', 'Sex work' and 'Test'. We conducted several scoping searches to identify the most efficient search strategy, which we provide in "Annex 1: Search strategy". Guidelines, reports and policy documents were searched using Google Scholar and employed to inform the discussion of findings. We exported all identified references (5036) into the bibliographic management software ENDNOTE X7.

The first author (AT) screened titles and abstracts against the following inclusion criteria: (1) published in a peer-reviewed journal between January 2000 and November 2017; (2) written in English; and (3) presenting data on HIV testing among FSWs. We excluded duplicates and studies for which no abstract or full text was available $(\mathrm{N}=17)$. After reviewing the full text of 95 pre-selected articles against the above mentioned inclusion criteria, 36 papers were retained for a more detailed review. The first author extracted data systematically using a standardized form that included information on the period of study, location, study population, design, research questions, key findings, and conclusions ("Annex 2: Data extraction form"). Next the quality of qualitative papers was assessed using the guide for critically appraising qualitative research by Spencer et al. [15]. The modified Downs and Black checklist was applied to quantitative and mixed-methods papers [16]. We used a midpoint score of 9 for qualitative papers and 12.5 for quantitative ones as a cut off between low- and high-quality studies. Overall, two quantitative papers with score of 10 [18] and 9 [17] points failed to meet the criteria; three papers received 12 points $[19,20]$. The vast majority of quantitative papers lacked information needed for assessment. We were unable to appraise four abstracts: three, for the limited data presented, and one, being a mathematical modeling paper [21] that did not fit well with the quality appraisal tools employed. We decided to include all papers into the review in order to provide a comprehensive picture; 

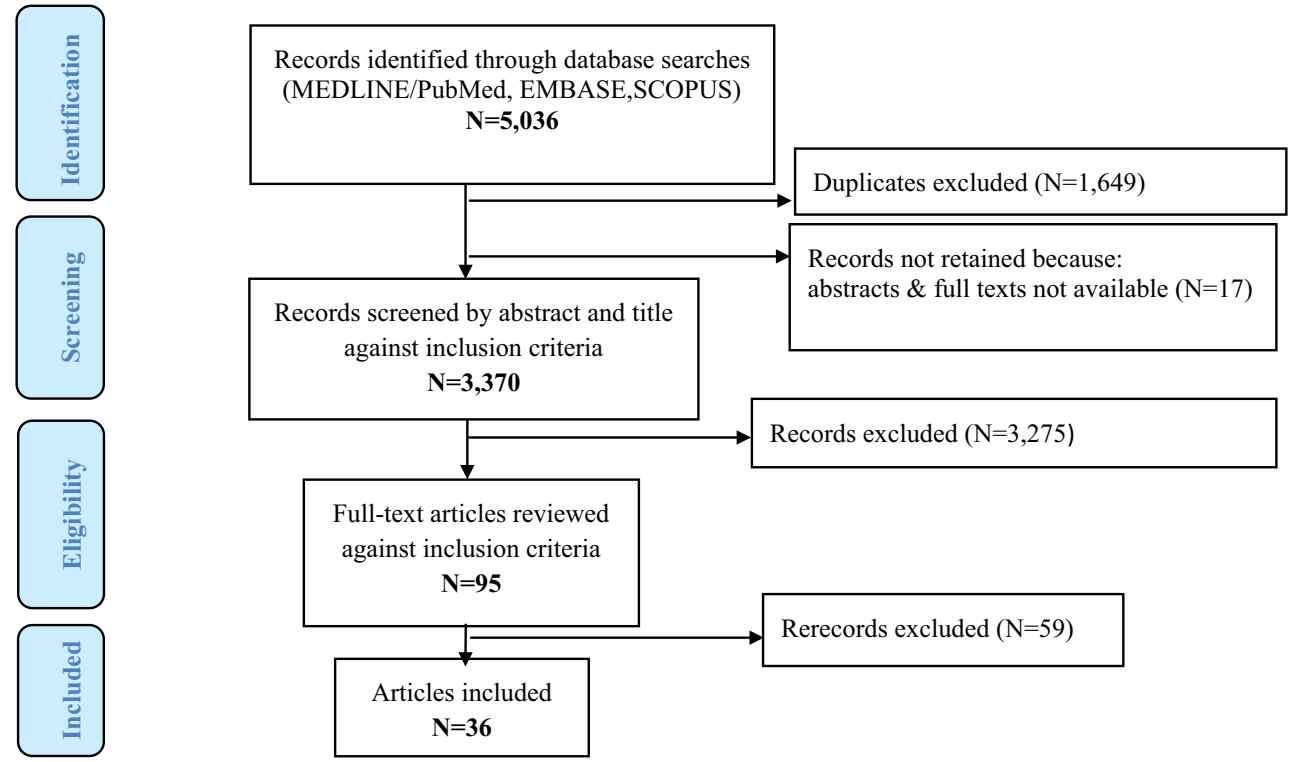

Fig. 1 PRISMA flow chart of citations

at the same time, we considered it important to stress the results of the quality assessment ("Annex 3: Quality assessment"). The results of the search and screening process are described in Fig. 1.

Guided by the socio-ecological model (SEM) developed by Blanchard et al. [22] we classified data into three levels: macro-, meso-, and micro-level factors (Table 1). The macro level consisted of economic and policy factors. The meso level included social networks, organizations, cultural norms, and values. The micro level included individual socio-demographic characteristics, knowledge, risk awareness, and behavioral factors. We also extracted data on previous experiences of HIV testing and ways to encourage uptake. The PRISMA check list is provided as "Annex 4: PRISMA 2009 Checklist”.

\section{Results}

Out of the 36 studies retained for review, most were quantitative $(\mathrm{N}=20)$ and conducted in Asia $(\mathrm{N}=18)$. Nine papers reported work conducted in Africa, three in Europe, three in Russia, and one in Macedonia. Three studies were conducted in Latin America, two in Canada and one in Australia. Eighteen studies were cross-sectional, and twenty-five focused exclusively on FSWs.

\section{Previous Experience of HIV Testing}

We summarized evidence on previous experience of HIV testing and approaches to facilitate testing (Table 1). Fifteen studies [17, 18, 23-35] focused on ever in life testing. The highest rate was reported in a study in Russia where all recruited FSWs $(100 \%, \mathrm{~N}=29)$ were tested [24] followed by Kenya (88.6\%, $\mathrm{N}=818$ ) [27]. The lowest rate was reported in a study conducted in India $(7.9 \%, \mathrm{~N}=6648)$ [18]. Ten studies examined recent testing [25, 27-29, 35-40], which varied extensively from $76.1 \%$ in Canada $(\mathrm{N}=435)$ [25] to $22 \%$ in China $(\mathrm{N}=970)$ [38]. Six studies addressed willingness to test [18-20, 28, 41, 42], and this ranged from $88 \%$ $(\mathrm{N}=17)$ in China [41] to $73.2 \%$ in India $(\mathrm{N}=6648)$ [18]. Three studies reported that willingness facilitated actual HIV testing [20, 28, 41]. Only four studies assessed frequencies of collecting test results [23, 26, 33, 43], and these ranged widely from $92.3 \%$ in Guinea [26] to $14.8 \%$ in Thailand [43].

We identified a high variability of outcome measures employed in the studies reviewed. For example, the frequency of HIV testing was measured using different time frames and included "last month" and "recent testing" with a time period corresponding to "recent" that varied from 1 year to 1 month.

\section{Conceptual Framework: Barriers and Facilitators of HIV Testing Amongst FSWs}

In this study we employed an adapted version of the socioecological framework developed by Blanchard et al. [22] to organize and analyze our findings systematically. As shown in Fig. 2, we conceptualized HIV test uptake as the result of a number of interrelated factors that operate simultaneously at the micro, meso and macro levels. Most articles focused 


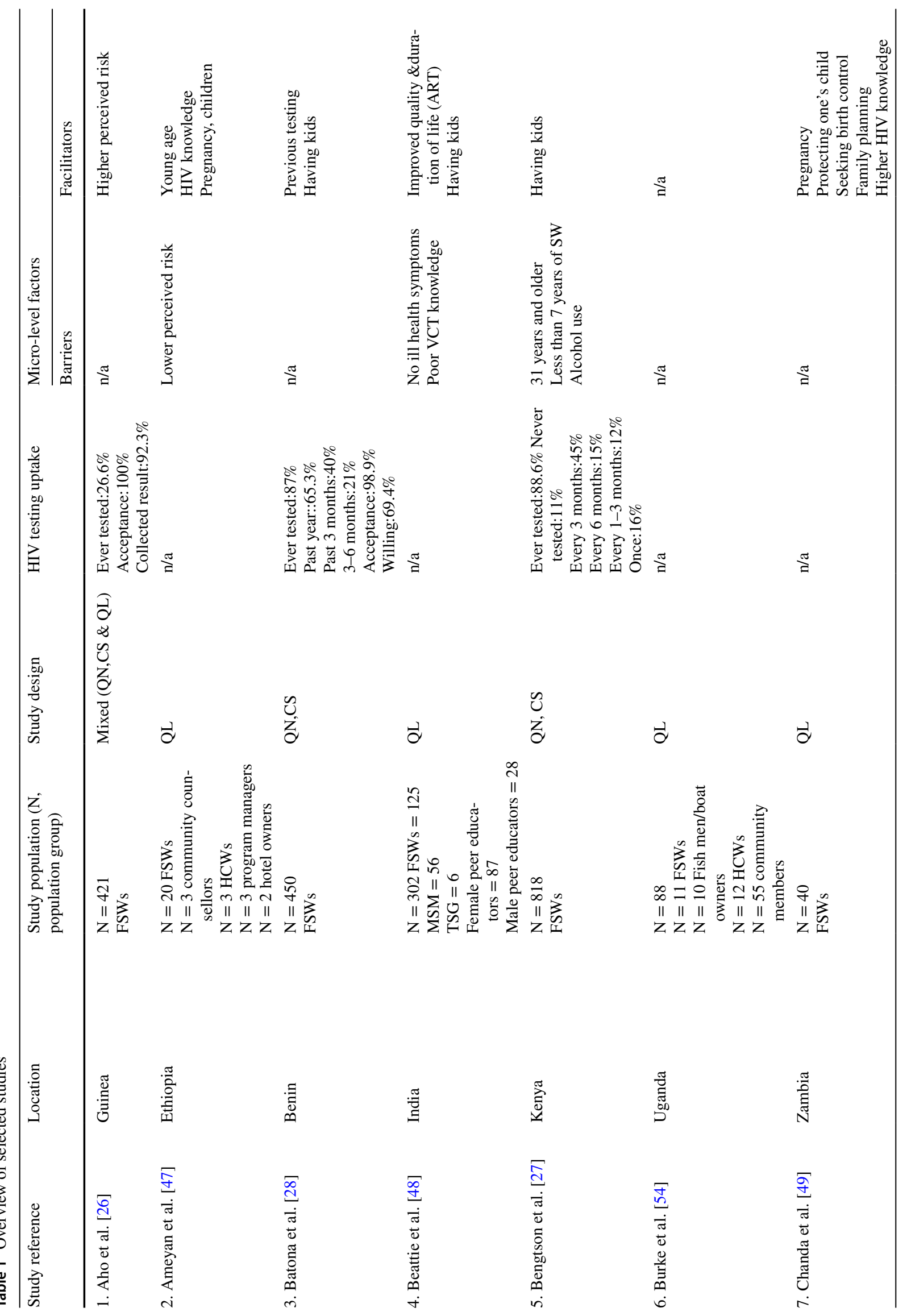




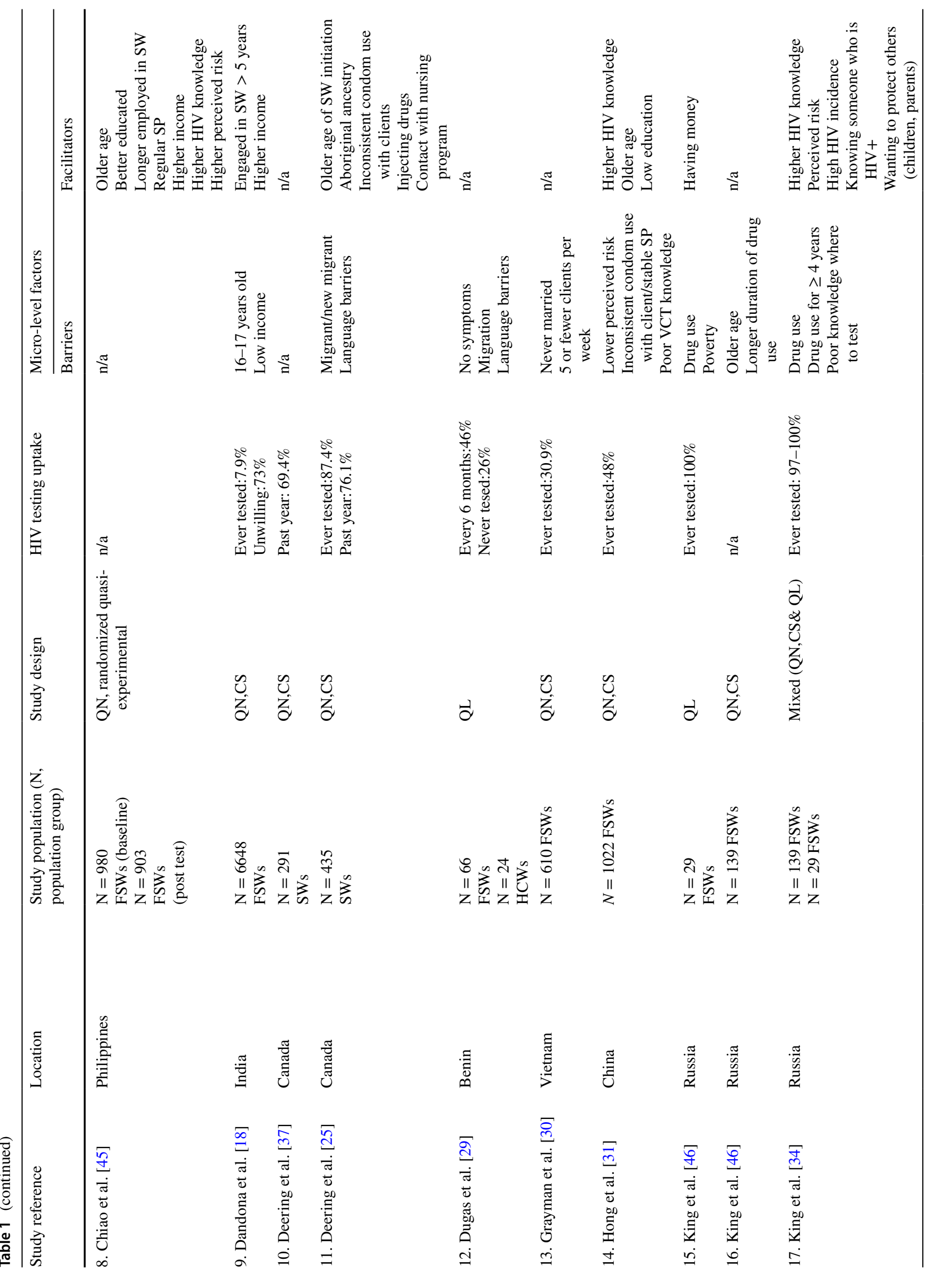




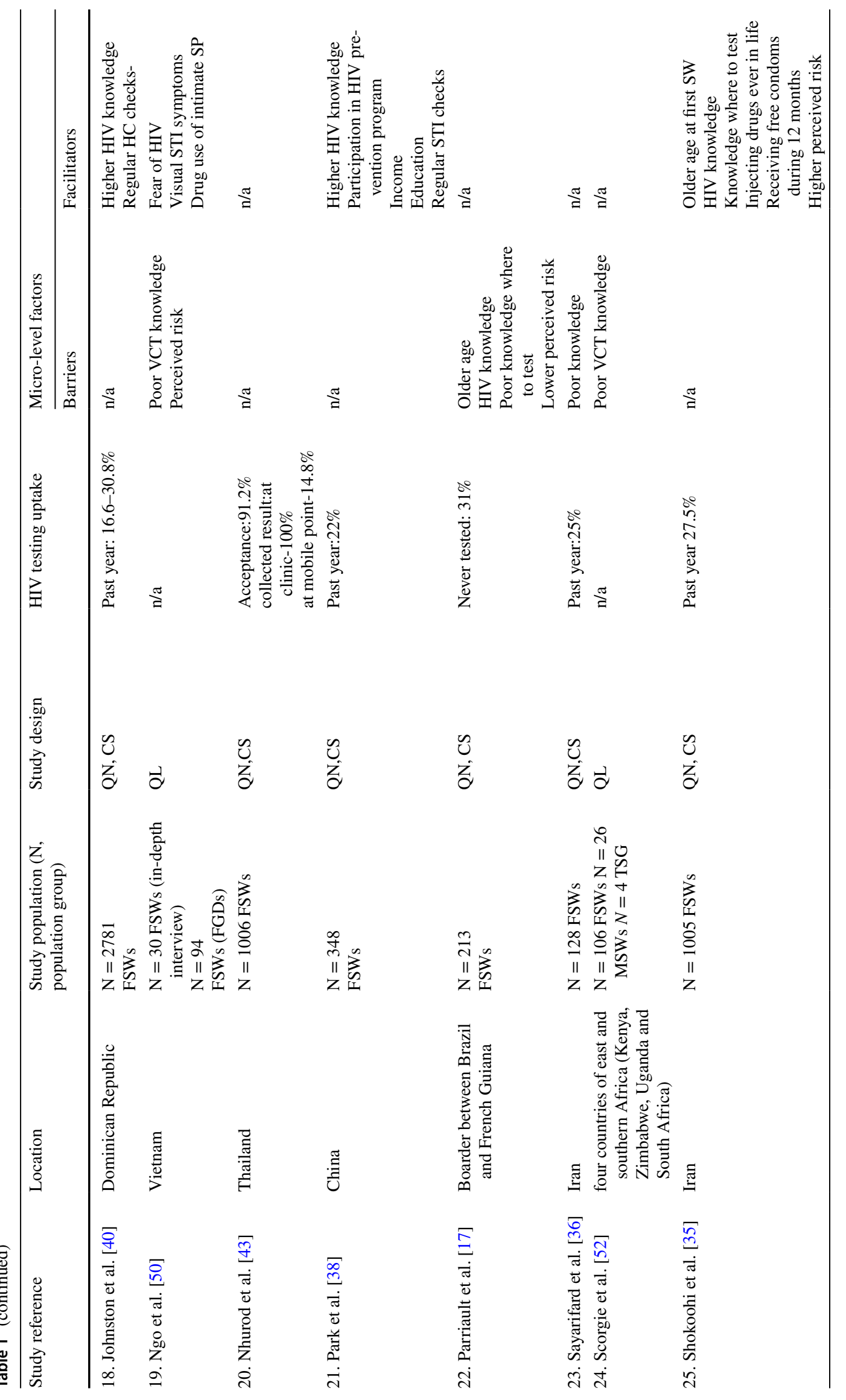




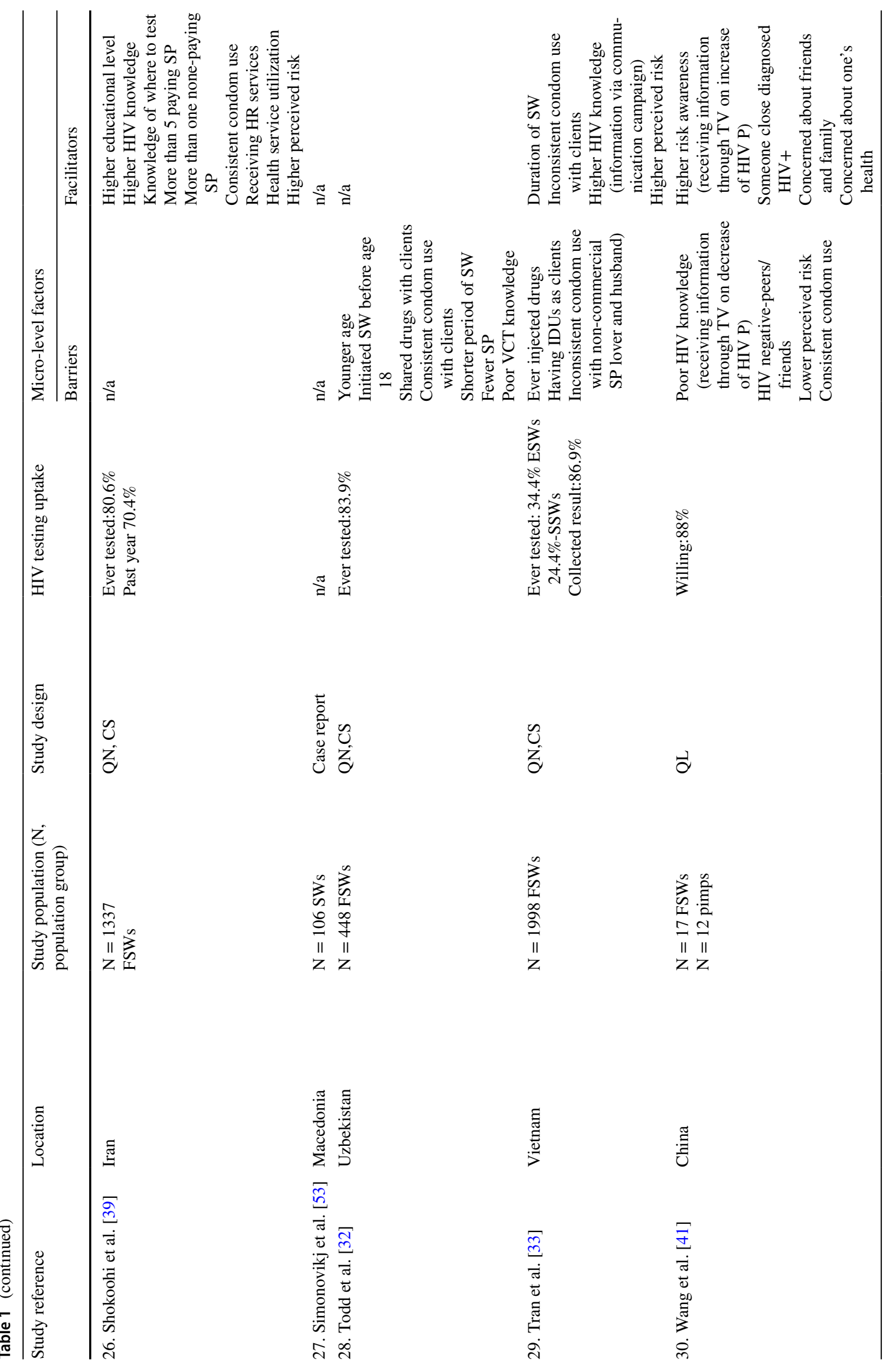




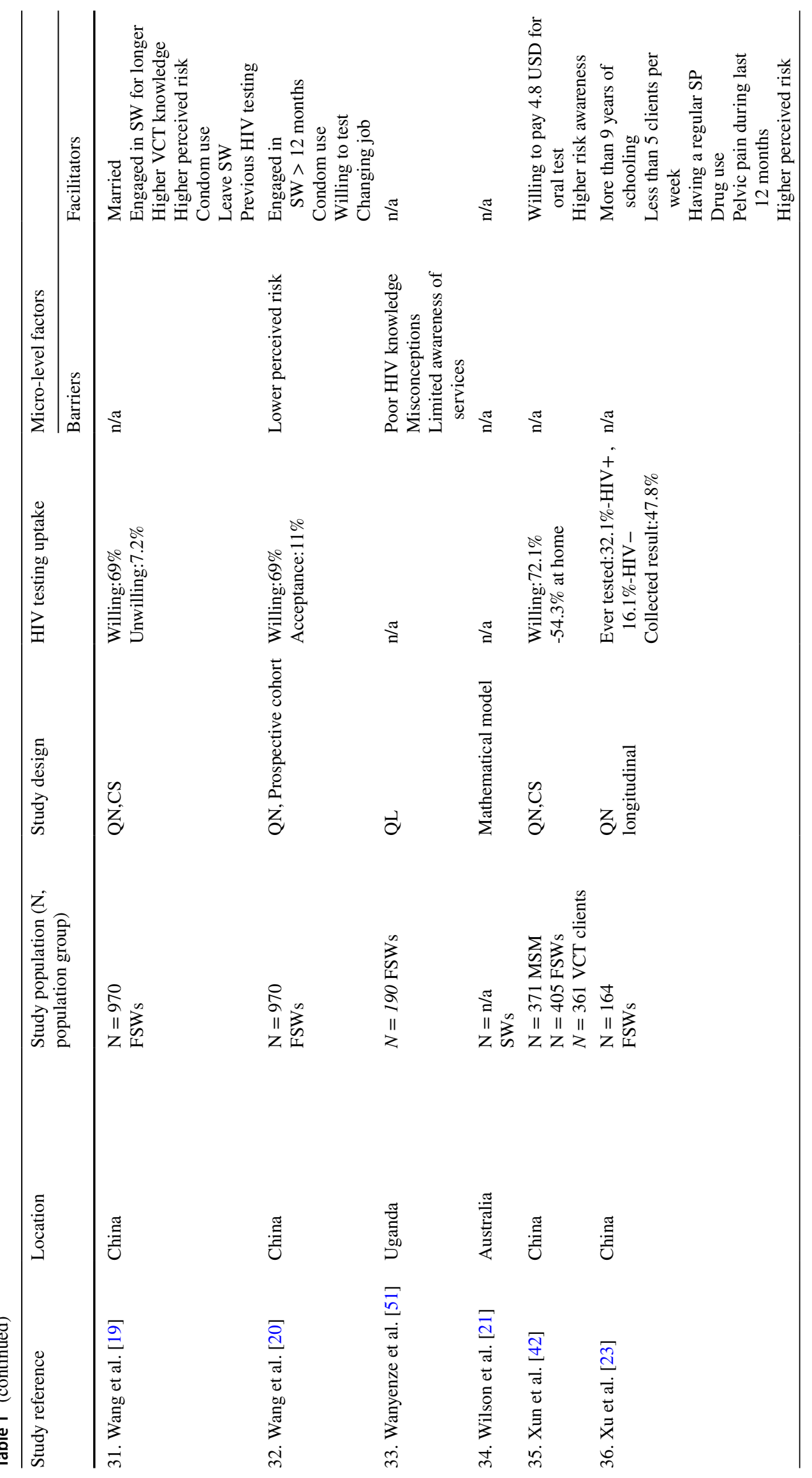




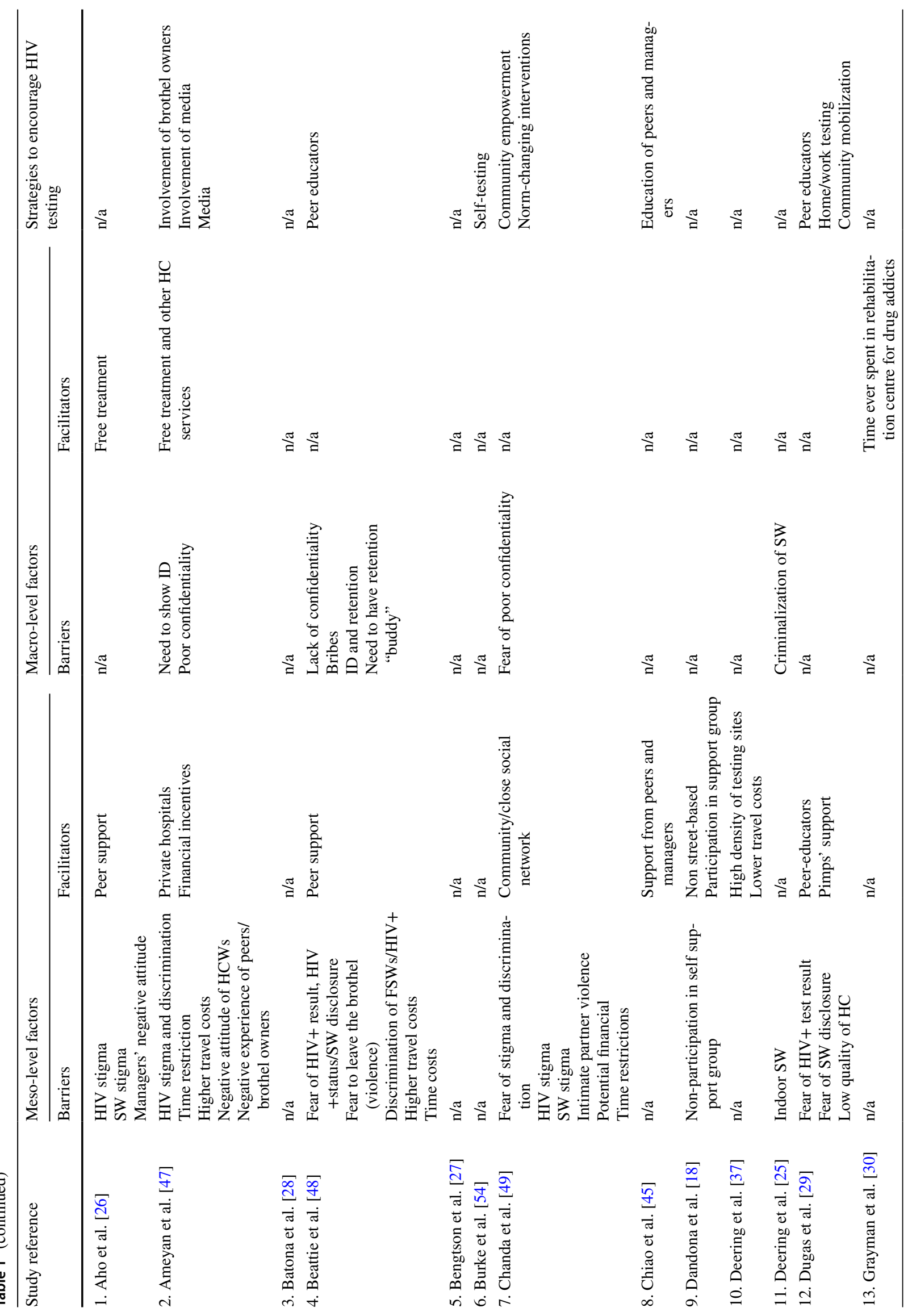




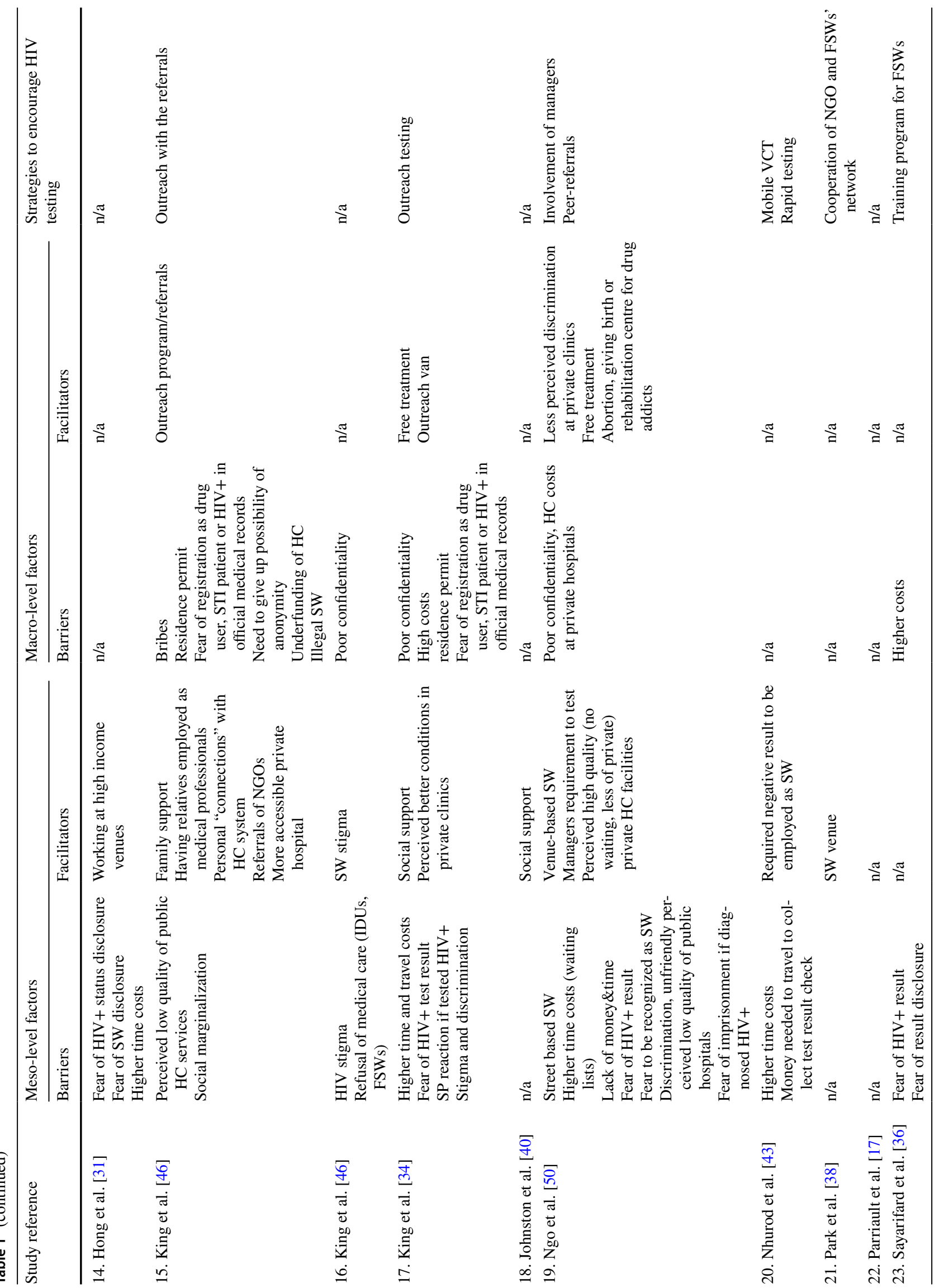




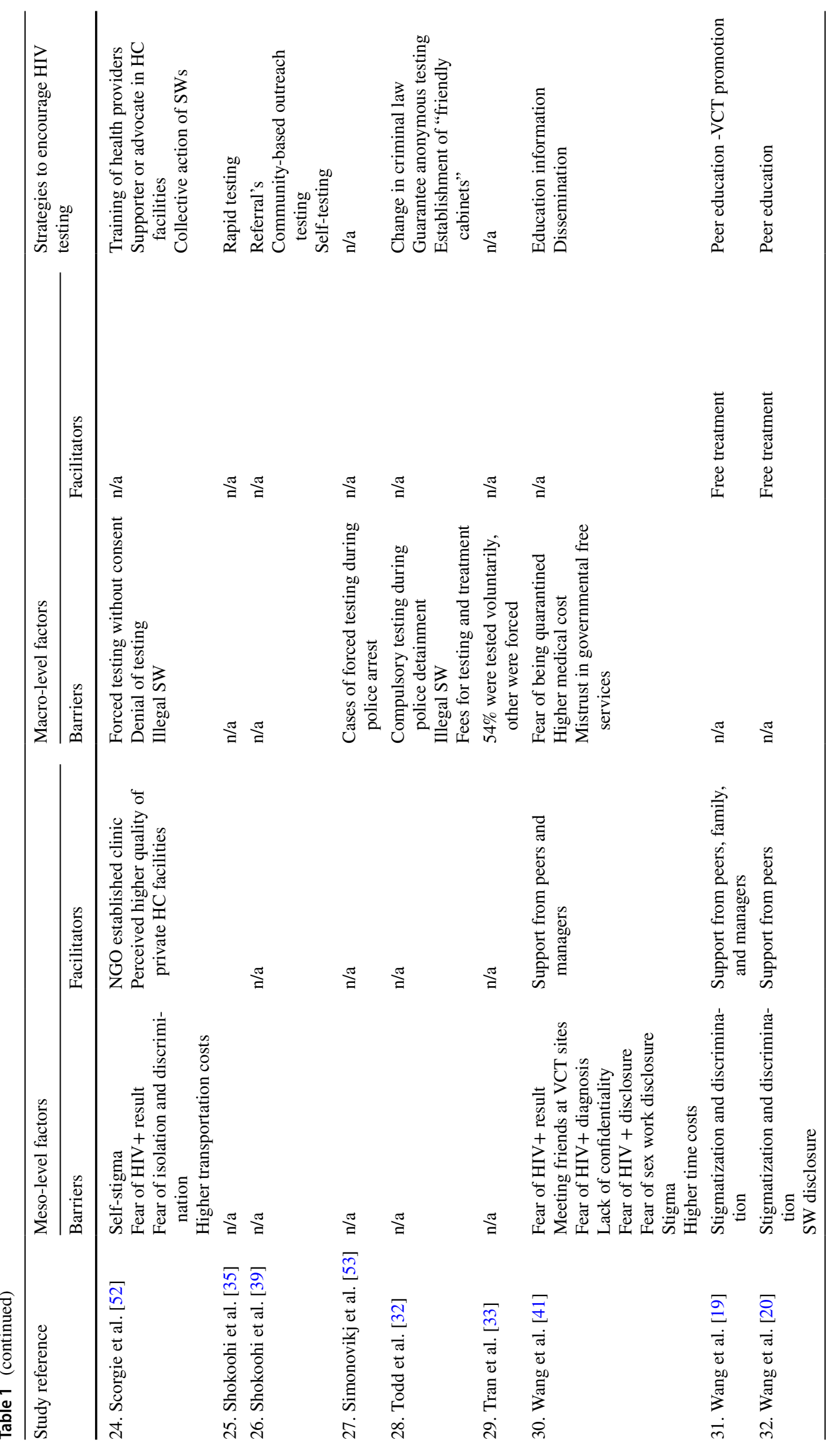




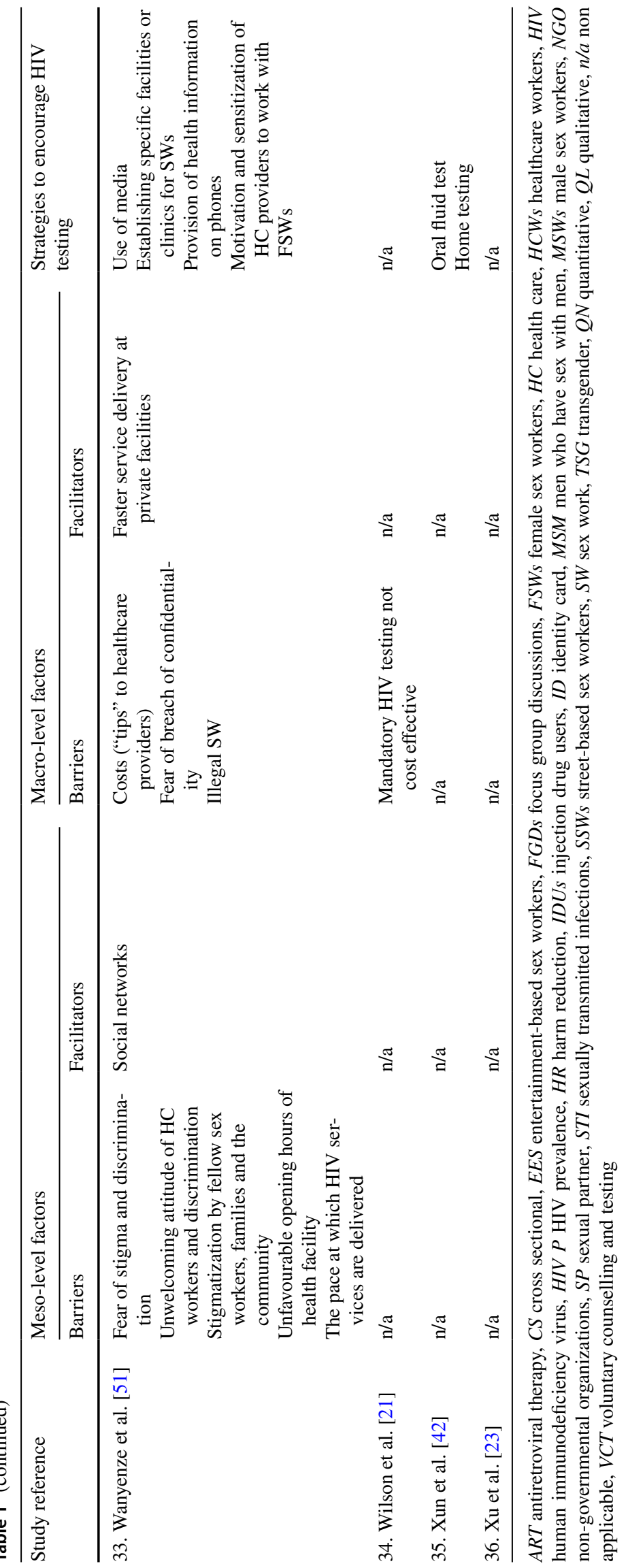




\section{MACRO LEVEL}

HIV testing policies: mandatory testing, forced testing, non-anonymous testing, lack of confidentiality, guarantee retention to treatment

Health care funding: health care entitlements, free ART, formal and informal payments.

Criminalization: criminalization of sex work/drug use.

\section{MESO LEVEL}

Sex work venue: level of income generated by sex work venues, indoors/outdoors.

Social network: support and attitude of peers, sex work managers, family.

Stigma and discrimination: fear of being identified as $\mathrm{HIV}+$, fear of imprisonment if testing $\mathrm{HIV}+$, fear to disclose history of sex work/drug use, discrimination from health care providers, discrimination from family members, self-stigmatization, negative perceptions about the quality of health care.

Costs (transport and time): time constraints, density of HIV testing sites, travel costs to collect results.

\section{MICRO LEVEL}

Socio-demographic characteristics: education, age, income level, family status, migration status. Risk behaviors: type and number of sexual partners, condom use, age at sex work initiation and period of engagement in sex work, drug and alcohol use.

Risk awareness: perceived personal risk of HIV infection, perception about HIV prevalence

HIV related knowledge: knowledge about HIV and available testing services.

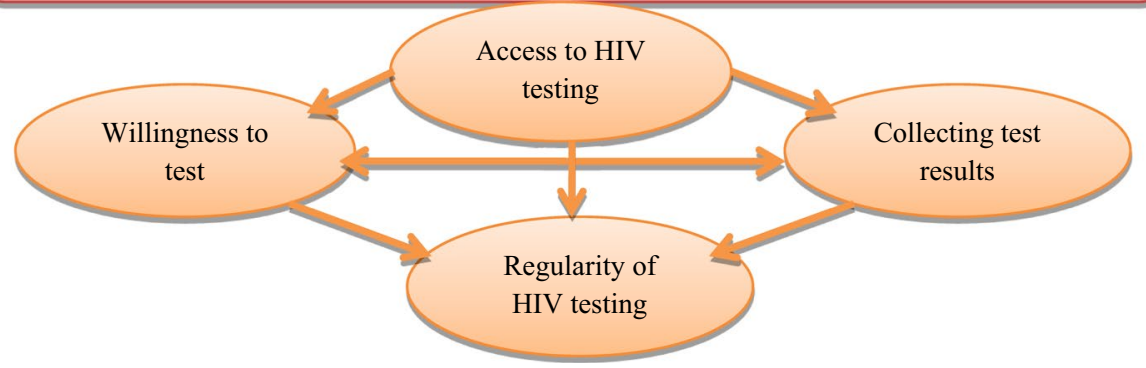

Fig. 2 Conceptual framework: barriers and facilitators of HIV testing amongst FSWs. Reproduced with Permission from Blanchard et al. [22]

on the micro $(\mathrm{N}=30)$ and meso $(\mathrm{N}=24)$ levels, and about half of all papers addressed the macro $(\mathrm{N}=19)$ level. Ten studies analyzed concurrently two levels of the social ecology, while nine addressed simultaneously the micro, meso, and macro levels.

\section{Micro-level Factors}

\section{Socio Demographic Characteristics}

Sixteen articles focused on socio-demographic characteristics. We found no consistent associations [18, 27, 31, 32, 44-46] of education and age [23, 31, 45] with HIV testing uptake. Highly educated women in the Philippines and Iran were more likely to test $[39,45]$, but studies in China reported higher HIV testing uptake amongst women with both high [23] and low education level [31]. In two studies conducted in China and one in the Philippines, older age facilitated HIV testing [31, 44, 45], but in Russia, Ethiopia and Kenya older-aged FSWs [46, 47] and those aged +30
[27] were less likely to test compared to younger FSWs. In Uzbekistan and India, younger age decreased testing [18, 32]. Higher income was associated with testing in India and the Philippines [18, 45] and in Russia poverty impeded access to healthcare, including HIV testing [24].

Ten studies reported that having children and/or being pregnant and/or being in a permanent relationship facilitated HIV testing [19, 23, 27, 28, 30, 34, 45, 47-49]. Married women in China [19] and those with a regular sexual partner in the Philippines [45] and in China [23] were more likely to test. According to a study conducted in Vietnam, unmarried women were less likely to test [30]. In Kenya, Zambia, Benin, Ethiopia, Russia and India, having children or being pregnant facilitated HIV testing [27, 28, 34, 47-49]. In Iran, incarceration was associated with recent testing [39].

In Canada and Benin, migrant FSWs [25, 29] had limited access to healthcare because of language barriers, which led to low HIV testing rates. 


\section{Risk Behaviors}

Seven studies reported nearly inconsistent patterns on how regular condom use influenced HIV testing. Using condoms during every instance of each sexual intercourse both facilitated and impeded testing depending on the type of sexual partner [19, 20, 25, 31, 33, 39, 41]. Three articles reported that inconsistent condom use with a client -facilitated testing [25, 31, 33], but using condoms inconsistently with a husband or lover was negatively associated with testing [33]. In China, a quantitative study identified that condom use was associated with HIV testing [20], although in a previous qualitative study the same author found that FSWs who used condoms consistently felt to be sufficiently protected from HIV and not in need of testing [41]. In Iran, consistent condom use during each sexual intercourse was associated with recent testing [39].

Initiation of sex work at an older age [18, 20, 33, 35, 45] and engaging in sex work for a longer period of time [18, 20, 33, 45] facilitated HIV testing. In Uzbekistan, FSWs who started sex work before the age of 18 were less likely to test [32], and in Canada older age of sex work initiation was positively associated with recent testing [25]. FSWs who engaged in sex work for a longer time had a higher uptake of testing [18, 20, 33, 45] and willingness to test [19]. FSWs employed for shorter periods [27, 32] were less likely to test.

Having a lower number of clients/sexual partners was associated with HIV testing in China [23], but was reported to decrease testing in Vietnam [30], Iran [39] and Uzbekistan [32].

Most studies identified drug use and alcohol consumption to impede HIV testing [24, 25, 27, 32-34, 46]. Still, in Iran and Canada drug use among FSWs did not hinder testing $[25,35]$.

\section{Risk Awareness}

We reviewed thirteen articles that focused on individual perceptions towards HIV risks [19, 20, 23, 26, 31, 33-35, $39,41,45,47,50]$. Low perceived risk was associated with lower likelihood to test [31, 45, 47], and FSWs would be less likely to test if they believed that HIV prevalence to be decreasing and no one in their social network was infected [41]. Conversely, high perceived risk was associated with HIV testing [19, 23, 26, 33-35, 39, 41, 45, 50].

\section{HIV-Related Knowledge}

Seventeen articles examined HIV knowledge, including knowledge of available HIV testing sites in the area [19, 29, 31, 33-36, 38-41, 45, 47-51]. FSWs who had heard prevention messages in HIV communication campaigns were more likely to test $[33,47,51]$. Similarly, FSWs were reluctant to test if they had poor HIV-related knowledge [29, 36, 41, 48, $49,51]$ and were not well informed about local testing sites [31, 41, 48, 50-52].

\section{Meso-level Factors}

\section{Sex Work Venue}

Of the six articles that addressed sex work venues [18, 25, $31,41,45,50]$, most reported that working indoors and at high-income venues generating higher income impelled HIV testing. Working in a high-income venue and out of the street predicted testing in China, Vietnam and India $[18,31,50]$. However, in Canada, FSWs working indoors were less likely to have recently tested for HIV than those working outdoors [25].

\section{Social Support}

About half of the articles reviewed assessed how FSWs' social interactions influenced their decision to test for HIV [18-20, 24, 26, 29, 34, 38, 40, 41, 43, 45, 47-51]. Positive attitudes and support from peers, family and partners facilitated HIV testing [19, 20, 24, 26, 29, 34, 40, 41, 45, 48-51]. In China, women were more likely to test if accompanied by peers [19, 20]. In Russia, family support was an important condition for accessing healthcare, including HIV testing, as women could rely on their family financially and emotionally [24]. Participation in self-support groups in India [18] and Uganda [51] and receiving condoms from HIV prevention programs in China [38] facilitated testing. Positive views of FSWs' employers towards HIV testing [41, $45]$ or requiring the test $[43,50]$ increased the uptake. However, in China and Ethiopia, employers expressed concerns towards HIV testing and how it could impact the sex work business [41, 47]. In Guinea, HIV testing was forbidden by some managers [26]. In Zambia and Russia, fear of negative reaction of their sexual partner if diagnosed HIV-positive, prevented women from engaging in HIV testing [34, 49].

\section{Stigma and Discrimination}

A total of fourteen articles focused on stigma and discrimination of HIV+ people and/or sex workers [20, 24, 26, 29, $31,34,36,41,46-52]$. Fears of being identified as HIV+ $[24,26,31,34,36,41,47-51]$ or as a sex worker $[20,26$, $31,34,41,46-52]$ were reported as barriers to testing in a number of studies. FSWs could refuse HIV testing [29, 36, $41,48,50,52]$ or fail to collect test results [48] if afraid of receiving an $\mathrm{HIV}+$ diagnosis.

In Benin, healthcare workers reported that women did not like to be recognized as FSWs, and that this could prevent them from seeking healthcare [29]. In several African 
countries, health providers discriminated against sex workers and their family members [52]. In Russia, FSWs were concerned that they would be treated badly or denied healthcare if identified as sex workers or drug users [46]. In China, FSWs worried about meeting an acquaintance at the testing site and being recognized as HIV+ [41], while in Vietnam, they feared imprisonment if diagnosed with HIV [50]. Selfstigma resulting from widespread negative views of HIV+ people and sex work decreased testing across several African countries [52]. Thirteen articles reported that anticipated stigma and discrimination at health facilities hampered service utilization [19, 20, 24, 26, 29, 37, 41, 46, 48-52]. In Russia, Vietnam, Uganda and several African countries, private hospitals were defined by FSWs as more friendly and of higher quality than public health facilities, and were reported to be preferable places to get healthcare services, including HIV testing [24, 50-52].

\section{Time and Transport Costs}

Eleven articles reported that time and transport costs hampered access to healthcare $[24,31,34,36,37,41,43,47$, 49-52]. Time restraints impeded testing in China [31, 41], India [48], Thailand [43], Vietnam [50], Uganda [51], Zambia [49], Ethiopia [47] and several other African countries (Kenya, Zimbabwe, Uganda and South Africa) [52]. In Uganda, Zambia and Russia, FSWs expressed dissatisfaction with opening hours of health facilities as they did not correspond with women's schedules and caused financial and time loss [34, 49, 51]. In Canada, higher density of testing sites and little time needed to get there were associated with having tested recently [37]. In Thailand, travel costs were reported to prevent users from collecting their HIV test results [43].

\section{Macro Level Factors}

\section{HIV Testing Policies}

Eleven articles focused on HIV testing policies [21, 24, $32,34,41,46-48,50-52]$ pointed to shortcomings in the range of services that should be provided together with HIV testing. These include informed Consent, Confidentiality, Counseling, Correct test results, and Connection to care and treatment, known as the " $5 \mathrm{Cs}$ " principles [3].

In China [41], Vietnam [50], India [48], Uganda [51], Zambia [49], Ethiopia [47] and Russia [46], lack of confidentiality was reported as a major barrier to HIV testing. Unwillingness to be included in official registers of HIV+ people decreased access to testing in China [41] and Russia [24]. In Russia, FSWs without a residence permit or passport are not entitled to accessing healthcare. Free-of-charge HIV testing is available only upon giving up anonymity, and if a woman utilizes state-sponsored HIV testing at a local clinic, the results are officially recorded into her personal medical records [24]. In India and Ethiopia, to access HIV and AIDS treatment, women are required to show an identity card [47, 48]. In Uganda, all women diagnosed HIV positive were given two papers indicating test result and further referrals while all diagnosed HIV negative were given one paper with test result only [51].

FSWs were forced to test against their will or were tested surreptitiously without consent in Kampala (Uganda), Hillbrow and Limpopo (South Africa) [52] and during police detainment in Uzbekistan [32] and Macedonia [53]. In Vietnam, among the FSWs who tested for HIV, only 54\% did it voluntarily [33]. FSWs who had spent time in rehabilitation or detention centers $[24,30,50]$ or had ever been pregnant $[24,50]$ were more likely to have undergone HIV testing. In Victoria, Australia, screening of sex workers is mandatory despite its lack of cost-effectiveness [21].

\section{Healthcare Funding}

Eleven articles reported how limited healthcare funding decreased HIV testing [19, 20, 24, 26, 32, 36, 41, 48, 50-52]. High medical care costs in China [41], Iran [36], several African countries (Kenya, Zimbabwe, Uganda and South Africa) [52] and informal payments in Russia [24], Uganda [51] and India [48] reduced access to healthcare, including testing. Five articles suggested that free treatment might increase testing $[19,20,26,47,50]$.

\section{Criminalization}

Eight studies reported how current criminalized approaches to sex work and drug use inhibited FSWs from accessing healthcare [24, 25, 27, 32, 34, 51, 52, 54]. Sex work criminalization in Kenya, Zimbabwe, Uganda and South Africa, Canada, Uzbekistan and Russia [24, 25, 27, 32, 51, 52, 54] and fear of registration as a drug-user in Russia [24, 34] are seen to have hampered access to healthcare, including testing.

\section{Testing Modalities}

A total of twenty studies examined different ways to encourage HIV testing among FSWs including self-testing [39, 54], home-based [25, 29, 42], rapid testing [35, 43], workbased [29], oral fluid tests [42], "friendly cabinets" (newly established anonymous testing centers) at public STI clinics [32, 51], mobile services [43], outreach with referrals [24, 34, 39], community mobilization [29, 52], community empowerment [49] and involvement of peers, managers and healthcare workers [19, 20, 39, 45, 47, 49-52]. In one study examining hypothetical circumstances around self-testing, 
participants reported to anticipate significant benefits (entire privacy, avoiding travel and time costs, ability to test before sex early diagnosis), although these same features raised concerns when associated with lack of supportive counseling and linkage to care [54].

These studies suggest that HIV testing might increase if FSWs can easily access testing sites and receive support from peers, friends and healthcare workers along with educational activities [19, 20, 45, 50-52].

\section{Discussion}

This systematic review of barriers and facilitators to HIV testing amongst FSWs found that the two barriers to HIV testing most commonly reported are (1) costs, including transportation, formal/informal payments, and time, and (2) stigma, including fear of involuntary disclosure of HIV status/history of sex work, negative attitudes of healthcare workers, and discriminatory policies. Social support facilitated HIV testing, with consistently higher uptake amongst married FSWs, and those encouraged to test by peers, healthcare workers or employers.

The majority of the studies reviewed were conducted in low and middle-income countries with only three studies identified in high-income settings. Only one study evaluated the cost-effectiveness of HIV testing amongst FSWs. Most studies addressed micro, or micro and meso levels of the SEM with predominance of micro-level factors. Thirteen studies analyzed concurrently the macro, meso and micro levels. Our findings support previous calls to develop HIV testing strategies that fully account for structural factors $[55$, 56] and highlight the need for a more nuanced investigation of how micro-, meso- and macro-level factors intersect to influence HIV testing uptake.

Few studies assessed frequencies of collecting test results or compared them with testing frequencies. The outcome most frequently assessed was "ever in life" testing although this outcome measure fails to capture the frequency of HIV testing. Furthermore, the highest percentage of recently tested FSWs was reported by a Canadian study and constituted $76.1 \%$, an outcome too low to meet either WHO recommendations [3, 57] or the "90-90-90" target [1], which highlights necessity to increase efforts to promote HIV testing amongst FSWs. Taken together, our results suggest addressing simultaneously several outcome measures when assessing HIV testing programs among female sex workers, including accessibility of testing, willingness to be tested, regularity and collecting test results.

In line with previous studies of HIV testing behavior of different populations $[14,58,59]$, we found that scarcity of financial resources, low perceived risk and poor HIV knowledge were barriers to HIV testing for FSWs.
Similar to the results reported for female migrants [58], we observed an association between having children and HIV testing uptake. This might be manifestation of women's and particularly pregnant women's greater exposure to HIV testing, as an offer of HIV testing became generally the norm in reproductive and antenatal care settings [3, 60]. On the other hand, several papers reviewed suggested that women in permanent relationships and with children might have higher motivation to stay healthy and thus, might seek out testing themselves. For example, in Vietnam, FSWs in permanent relationships were more likely to be tested in the year 2000 before HIV testing became widely implemented as a part of national antenatal health care program across the country [61]. Overall, social support from family, peers, sex work managers and healthcare workers are instrumental for promoting HIV testing uptake among FSWs, yet the same sources might contribute to further stigma and discrimination.

We did not find any consistent associations between age of participants [58] or their educational level [58, 59] and HIV testing, but working in the sex industry for a longer period and starting sex work at older ages were associated with higher HIV testing uptake. These findings suggest that the willingness to test for HIV might increase with time and relate closely with HIV risk awareness.

The inconsistency of results on how condom use and number of clients influenced testing might be explained by FSWs' engagement in different types of concurrent sexual partnerships. While using condoms with commercial clients might be perceived as prevailing acceptable behavior [62], the decision to use a condom in cohabiting relationships or with a husband might be influenced by interpersonal factors related to partnership intimacy (e.g., trust, emotional closeness, power or reproductive desires) [63]. Moreover, there is a need to account not only for the type of partnerships, but also for their duration. Consistency of condom use might decrease with longer duration of relationships with non-paying partners [63], but may increase with commercial permanent partners [64]. The relationship intimacy may be at play in the HIV testing decision-making process among FSWs and for consistent condom use. Testing behavior might be influenced by increased trust, emotional closeness and familiarity. A more nuanced understanding of how HIV testing behavior is influenced by risky sexual behaviors in different types of partnerships and how it changes over time is needed. In turn, relationship power might be an important modifiable factor, which might be considered when developing HIV testing interventions for FSWs.

The inconsistencies between results in relation to sexual/ drug use behavior and HIV testing might be due to differences in targets of HIV testing approaches across countries. For example, in Canada efforts were concentrated on reaching street-based sex workers and those injecting drugs, 
leaving out those working indoors, in more high-income venues. Nevertheless, at that time sex work was fully decriminalized in Canada [65]. In contrast, in Uzbekistan and Russia HIV testing might be less accessible for sex workers and drug users because of punitive laws. In these countries, HIV testing is provided solely through government-affiliated settings, including so-called "friendly cabinets" and thus, sex workers and drug users might avoid state clinics or at least avoid disclosing who they are, as they might be stigmatized by healthcare providers or even arrested. Our results demonstrate how laws might diminish promising health-promoting interventions in some countries while in others, supporting policies and concentrated efforts might lead to the successful enrolment of most vulnerable populations.

Furthermore, factors, such as violations of human rights when forcing FSWs to test, lack of confidentiality and anonymity, discriminatory attitudes of healthcare workers, fear of testing HIV+ and being identified as a sex worker and/or a drug user, are manifestations of prevailing stigma. Unfortunately, there are still cases where the violation of basic human rights is "justified" and sex workers are perceived as victims and objects of pity, who should be helped when applying mandatory or forced testing. Our findings highlight the importance to tackle overlapping stigma and discrimination across all three levels of SEM in order to promote HIV testing among sex workers [66]. This is in line with the WHO's call to enforce the 5 Cs principles and to institutionalize policies preventing discrimination and promoting tolerance towards sex workers and people living with HIV $[61,67]$. As reported before, introduction of discriminative laws and policies criminalizing sex work and/or HIV transmission may fuel stigma [65, 68-70].

This review has several limitations. It is restricted to studies published in English, but only three pre-selected studies were excluded for this reason, so the impact upon the findings is likely to be minimal. We included studies published during the last 17 years to account for recent HIV testing approaches. It is unlikely that the content of previously published articles would have substantially altered our findings, as rapid HIV testing started in the early 2000s. We excluded eight citations with neither abstract, nor title available. We acknowledge that our findings are based on the topics presented by the selected studies, and thus, are restricted by the reported information. Despite the limitations mentioned above, this study provides a broad overview of the different aspects of HIV testing across the global SEM, provides important insights on how HIV testing uptake could be promoted among FSWs, and suggests avenues for further research.

\section{Conclusion}

The consistent finding that social support facilitated HIV testing calls for the inclusion of meso- level factors into current HIV testing strategies directed at FSW. Studies on the role of macro-level factors and their intersections with the meso and micro levels are needed to inform interventions that facilitate HIV testing uptake amongst FSWs.

Acknowledgements AT was financed by the TransGlobal Health Program as a part of the Erasmus Mundus Joint Doctorate Programme. MR received funds from the Spanish Ministry of Economy and Competitiveness (MINECO) as part of a "Ramon y Cajal" fellowship (RYC-2011-08428), and the Agència de Gestió d'Ajuts Universitaris $i$ de Recerca, Regional Government of Catalonia (AGAUR Grant 2014SGR26). I would like to thank Jacob Osborne, MSc Research Master Global Health, for his help with editing this paper. I would like to thank Alyona Mazhnaya, Department of Health, Behavior \& Society, Johns Hopkins Bloomberg School of Public Health Baltimore, USA, for helping with updating search. ISGlobal is a member of the CERCA Programme, Generalitat de Catalunya.

Author Contributions Conceived the study: MR, AT. Developed the search strategy: AT, MR. Conducted online database searches and screened data: AT. Extracted and analyzed the data: AT. Wrote the paper: AT. Contributed to writing the paper: MR. Provided critical comments on the manuscript: MR, JEB, JB. Approved the final version of the manuscript: AT, MR, JEB, JB.

Funding AT was financed by the TransGlobal Health Program as a part of the Erasmus Mundus Joint Doctorate Programme (ERASMUS MUNDUS 2009-2013, EMJD, Action 1B, Agreement No. 20130039). MR received funds from the Spanish Ministry of Economy and Competitiveness (MINECO) as part of a "Ramon y Cajal" fellowship (RYC-2011-08428), and the Agència de Gestió d'Ajuts Universitaris i de Recerca, Regional Government of Catalonia (AGAUR Grant 2014SGR26).

\section{Compliance with Ethical Standards}

Conflict of interest Author AT declares that she has no conflict of interest. Author JEWB declares that she has no conflict of interest. Author JB declares that he has no conflict of interest Author MR declares that she has no conflict of interest.

Ethical Approval This article does not contain any studies with human participants or animals performed by any of the authors.

Open Access This article is distributed under the terms of the Creative Commons Attribution 4.0 International License (http://creativeco mmons.org/licenses/by/4.0/), which permits unrestricted use, distribution, and reproduction in any medium, provided you give appropriate credit to the original author(s) and the source, provide a link to the Creative Commons license, and indicate if changes were made. 


\section{Annex 1: Search Strategy}

\begin{tabular}{|c|c|c|}
\hline $\begin{array}{l}\text { HIV (human Immu- } \\
\text { nodeficiency virus) } \\
\text { (AND combined } \\
\text { with) }\end{array}$ & $\begin{array}{l}\text { HIV testing/test/ } \\
\text { tested } \\
\text { (AND combined } \\
\text { with) }\end{array}$ & $\begin{array}{l}\text { Sex work } \\
\text { (AND combined with) }\end{array}$ \\
\hline $\begin{array}{l}\text { OR acquired immu- } \\
\text { nodeficiency syn- } \\
\text { drome OR AIDS }\end{array}$ & $\begin{array}{l}\text { OR voluntary coun- } \\
\text { selling and testing } \\
\text { OR VCT }\end{array}$ & $\begin{array}{l}\text { OR people who sell } \\
\text { sex }\end{array}$ \\
\hline \multirow[t]{8}{*}{$\begin{array}{l}\text { OR HIV } \\
\text { OR human immuno- } \\
\text { deficiency virus }\end{array}$} & $\begin{array}{l}\text { OR provider initiated } \\
\text { testing and coun- } \\
\text { selling OR PITC }\end{array}$ & $\begin{array}{l}\text { OR sex industry/sex } \\
\text { business }\end{array}$ \\
\hline & $\begin{array}{l}\text { OR provider initiated } \\
\text { counselling and } \\
\text { testing OR PICT }\end{array}$ & OR prostitution \\
\hline & $\begin{array}{l}\text { OR diagnostic/diag- } \\
\text { nosed }\end{array}$ & $\begin{array}{l}\text { OR FSW OR female } \\
\text { sex workers }\end{array}$ \\
\hline & $\begin{array}{l}\text { OR screening/ } \\
\text { screened }\end{array}$ & $\begin{array}{l}\text { OR CSW OR com- } \\
\text { mercial sex workers }\end{array}$ \\
\hline & $\begin{array}{l}\text { OR routine testing, } \\
\text { Opt-In, Opt-Out }\end{array}$ & OR sex services \\
\hline & OR positive result & OR escort services \\
\hline & $\begin{array}{l}\text { OR testing and coun- } \\
\text { selling OR HTC }\end{array}$ & OR paid sex \\
\hline & & OR transactional sex \\
\hline
\end{tabular}

The final search strategy was defined as:

(1) Search terms for HIV;

(2) Search term for Sex workers;

(3) Search term for HIV testing;

(4) 1 AND 2 AND 3.

Date of search: 03/November/2017;

Searched fields: abstract, key words, subject headings, title;

Databases searched:

Results: Ovid MEDLINE(R)-1,877studies

Embase-2516 studies

SCOPUS-2591 studies

1. HIV.ab,kw,sh,ti.

2. AIDS.ab,kw,sh,ti.

3. Human Immunodeficiency virus.ab,kw,sh,ti.

4. Acquired Immunodeficiency syndrome.ab,kw,sh,ti.

5. 1 or 2 or 3 or 4

6. "test* ".ab,kw,sh,ti.

7. "counsel*".ab,kw,sh,ti.

8. HTC.ab,kw,sh,ti.

9. VCT.ab,kw,sh,ti.

10. (Voluntary counsel* and test*).ab,kw,sh,ti.
11. (Provider Initiated test* and counsel*).ab,kw,sh,ti.

12. PITC.ab,kw,sh,ti.

13. PICT.ab,kw,sh,ti.

14. (Provider Initiated counsel* and test*).ab,kw,sh,ti.

15. "diagnos* ".ab,kw,sh,ti.

16. "screen* ".ab,kw,sh,ti.

17. "Routine test* “.ab,kw,sh,ti.

18. Opt-In.ab,kw,sh,ti.

19. OPt-Out.ab,kw,sh,ti.

20. Positive results.ab,kw,sh,ti.

21. 6 or 7 or 8 or 9 or 10 or 11 or 12 or 13 or 14 or 15 or 16 or 17 or 18 or 19 or 20

22. "Sex* work* ".ab,kw,sh,ti.

23. "people who sell sex* ".ab,kw,sh,ti.

24. "sex* industry ".ab,kw,sh,ti.

25. "sex* business ".ab,kw,sh,ti.

26. "sex* service* ".ab,kw,sh,ti.

27. "prostitut* ".ab,kw,sh,ti.

28. "female sex* work* ".ab,kw,sh,ti.

29. "commercial sex* work* ".ab,kw,sh,ti.

30. "Escort* service* ".ab,kw,sh,ti.

31. "paid sex* ".ab,kw,sh,ti.

32. "transactional sex* ".ab,kw,sh,ti.

33. "FSW* ".ab,kw,sh,ti.

34. " $\mathrm{CSW} *$ " ab,kw,sh,ti.

35. 22 or 23 or 24 or 25 or 26 or 27 or 28 or 29 or 30 or 31 or 32 or 33 or 34

36. 5 and 21 and 35

37. ("2000" or " 2001 " or " 2002 " or " 2003 " or " 2004 " or "2005" or "2006" or " 2007 " or " 2008 " or " 2009 " or “2010" or " 2011 " or "2012" or “2013" or "2014” or "2015" or "2016" or “2017").yr.

38. 36 and 37

\section{Annex 2: Data Extraction Form}

Title

Date published

Date of research

Authors

Study design

Research objectives/ research questions

Country

Study population

Main methods of research

Main results

Main conclusions

Comments*(if needed) 


\section{Annex 3: Quality Assessment}

The quality of the qualitative papers (Table 1) was assessed using the guide for critically appraising qualitative research [15].The checklist consisted of 18 items assessing findings, design, sample, data collection, analysis, reporting, reflexivity and neutrality, ethics and auditability. As in previous research [66] we used a midpoint score of 9 as a cut off between low- and high-quality studies.

We assessed the quality of the quantitative and mixedmethods papers using the modified Downs and Black checklist [16]. The 26 questions of the checklist represented items of reporting, external and internal validity, and power. As the majority of studies did not report power calculations of the sample size and none was single or double blinded, we excluded the power (\#27) and the blinding $(\# 13,14)$ questions. Thus, the modified checklist consisted of 24 questions with a maximum score of 25 points). A midpoint score of 12.5 was considered to distinguish the high-quality studies (Table 2).

Table 2 Quality assessment of the 36 studies

\begin{tabular}{|c|c|c|}
\hline Study reference & Study design & $\begin{array}{l}\text { Summary score for } \\
\text { quality assessment }\end{array}$ \\
\hline \multicolumn{3}{|c|}{ Qualitative methods (Spencer et al. [15]) } \\
\hline Ameyan et al. [47] & QL & $61 \%(11 / 18)$ \\
\hline Beattie et al. [48] & QL & $72 \%(13 / 18)$ \\
\hline Burke et al. [54] & QL & $61 \%(11 / 18)$ \\
\hline Chanda et al. [49] & QL & $67 \%(12 / 18)$ \\
\hline Dugas et al. [29] & QL & $50 \%(9 / 18)$ \\
\hline King et al. [46] & QL & $50 \%(9 / 18)$ \\
\hline Ngo et al. [50] & QL & $72 \%(13 / 18)$ \\
\hline Scorgie et al. [52] & QL & $67 \%(12 / 18)$ \\
\hline Wang et al. [41] & QL & $67 \%(12 / 18)$ \\
\hline $\begin{array}{l}\text { Wanyenze et al. } \\
\text { [51] }\end{array}$ & QL & $72 \%(13 / 18)$ \\
\hline \multicolumn{3}{|c|}{ Quantitative methods (modified Downs and Black [16]) } \\
\hline Batona et al. [28] & QN & $56 \%(14 / 25)$ \\
\hline Bengtson et al. [27] & QN & $52 \%(13 / 25)$ \\
\hline Chiao et al. [45] & QN & $72 \%(18 / 25)$ \\
\hline Dandona et al. [18] & QN & $40 \%(10 / 25)$ \\
\hline Deering et al. [25] & QN & $60 \%(15 / 25)$ \\
\hline Grayman et al. [30] & QN & $48 \%(12 / 25)$ \\
\hline Hong et al. [31] & QN & $52 \%(13 / 25)$ \\
\hline Johnston et al. [40] & QN & $64 \%(16 / 25)$ \\
\hline King et al. [46] & QN & $52 \%(13 / 25)$ \\
\hline Nhurod et al. [43] & QN & $56 \%(14 / 25)$ \\
\hline Parriault et al. [17] & QN & $36 \%(9 / 25)$ \\
\hline Shokoohi et al. [35] & QN & $56 \%(14 / 25)$ \\
\hline Shokoohi et al. [35] & QN & $60 \%(15 / 25)$ \\
\hline Todd et al. [32] & QN & $52 \%(13 / 25)$ \\
\hline Tran et al. [33] & QN & $52 \%(13 / 25)$ \\
\hline
\end{tabular}

Table 2 continued

\begin{tabular}{lll}
\hline Study reference & Study design & $\begin{array}{l}\text { Summary score for } \\
\text { quality assessment }\end{array}$ \\
\hline Wang et al. [19] & QN & $48 \%(12 / 25)$ \\
Wang et al. [20] & QN & $48 \%(12 / 25)$ \\
Wilson et al. [21] & QN, mathematical & n/a \\
\multicolumn{3}{c}{ modeling } \\
Xun et al. [42] & QN & $56 \%(14 / 25)$ \\
Xu et al. [23] & QN & $64 \%(16 / 25)$ \\
Mixed methods (modified Downs and Black [16]) \\
Aho et al. [26] & QN \& QL & $68 \%(17 / 25)$ \\
King et al. [34] & QN \& QL & $48(12 / 25)$ \\
Abstracts & & $\mathrm{n} / \mathrm{a}$ \\
Deering et al. [37] & QN & $\mathrm{n} / \mathrm{a}$ \\
Park et al. [38] & QN & $\mathrm{n} / \mathrm{a}$ \\
Sayarifard et al. & QN & \\
[36] & & $\mathrm{n} / \mathrm{a}$ \\
Simonovikj et al. & Case report & \\
[53] & &
\end{tabular}




\section{Annex 4: PRISMA 2009 checklist}

\begin{tabular}{|c|c|c|c|}
\hline Section/topic & \# & Checklist item & Reported (Yes/No) \\
\hline \multicolumn{4}{|l|}{ Title } \\
\hline Title & 1 & Identify the report as a systematic review, meta-analysis, or both. & Yes \\
\hline \multicolumn{4}{|l|}{ Abstract } \\
\hline Structured summary & 2 & $\begin{array}{l}\text { Provide a structured summary including, as applicable: background; objectives; } \\
\text { data sources; study eligibility criteria, participants, and interventions; study } \\
\text { appraisal and synthesis methods; results; limitations; conclusions and impli- } \\
\text { cations of key findings; systematic review registration number. }\end{array}$ & Yes \\
\hline \multicolumn{4}{|l|}{ Introduction } \\
\hline Rationale & 3 & Describe the rationale for the review in the context of what is already known. & Yes \\
\hline Objectives & 4 & $\begin{array}{l}\text { Provide an explicit statement of questions being addressed with reference } \\
\text { to participants, interventions, comparisons, outcomes, and study design } \\
\text { (PICOS). }\end{array}$ & Not applicable \\
\hline \multicolumn{4}{|l|}{ Methods } \\
\hline Protocol and registration & 5 & $\begin{array}{l}\text { Indicate if a review protocol exists, if and where it can be accessed (e.g., Web } \\
\text { address), and, if available, provide registration information including registra- } \\
\text { tion number. }\end{array}$ & Not available \\
\hline Eligibility criteria & 6 & $\begin{array}{l}\text { Specify study characteristics (e.g., PICOS, length of follow-up) and report } \\
\text { characteristics (e.g., years considered, language, publication status) used as } \\
\text { criteria for eligibility, giving rationale. }\end{array}$ & Yes \\
\hline Information sources & 7 & $\begin{array}{l}\text { Describe all information sources (e.g., databases with dates of coverage, con- } \\
\text { tact with study authors to identify additional studies) in the search and date } \\
\text { last searched. }\end{array}$ & Yes \\
\hline Search & 8 & $\begin{array}{l}\text { Present full electronic search strategy for at least one database, including any } \\
\text { limits used, such that it could be repeated. }\end{array}$ & $\begin{array}{l}\text { Yes (“Annex 1: Search } \\
\text { strategy”) }\end{array}$ \\
\hline Study selection & 9 & $\begin{array}{l}\text { State the process for selecting studies (i.e., screening, eligibility, included in } \\
\text { systematic review, and, if applicable, included in the meta-analysis). }\end{array}$ & Yes (Fig. 1) \\
\hline Data collection process & 10 & $\begin{array}{l}\text { Describe method of data extraction from reports (e.g., piloted forms, indepen- } \\
\text { dently, in duplicate) and any processes for obtaining and confirming data } \\
\text { from investigators. }\end{array}$ & $\begin{array}{l}\text { Yes (“Annex 2: Data } \\
\text { extraction form”) }\end{array}$ \\
\hline Data items & 11 & $\begin{array}{l}\text { List and define all variables for which data were sought (e.g., PICOS, funding } \\
\text { sources) and any assumptions and simplifications made. }\end{array}$ & Yes \\
\hline $\begin{array}{l}\text { Risk of bias in individual } \\
\text { studies }\end{array}$ & 12 & $\begin{array}{l}\text { Describe methods used for assessing risk of bias of individual studies (includ- } \\
\text { ing specification of whether this was done at the study or outcome level), and } \\
\text { how this information is to be used in any data synthesis. }\end{array}$ & Not available \\
\hline Summary measures & 13 & State the principal summary measures (e.g., risk ratio, difference in means). & Yes \\
\hline Synthesis of results & 14 & $\begin{array}{l}\text { Describe the methods of handling data and combining results of studies, if } \\
\text { done, including measures of consistency }\left(\text { e.g., } \mathrm{I}^{2}\right) \text { for each meta-analysis. }\end{array}$ & Not applicable \\
\hline Risk of bias across studies & 15 & $\begin{array}{l}\text { Specify any assessment of risk of bias that may affect the cumulative evidence } \\
\text { (e.g., publication bias, selective reporting within studies). }\end{array}$ & Yes \\
\hline Additional analyses & 16 & $\begin{array}{l}\text { Describe methods of additional analyses (e.g., sensitivity or subgroup analyses, } \\
\text { meta-regression), if done, indicating which were pre-specified. }\end{array}$ & Not available \\
\hline \multicolumn{4}{|l|}{ Results } \\
\hline Study selection & 17 & $\begin{array}{l}\text { Give numbers of studies screened, assessed for eligibility, and included in the } \\
\text { review, with reasons for exclusions at each stage, ideally with a flow diagram. }\end{array}$ & Yes (Fig. 1) \\
\hline Study characteristics & 18 & $\begin{array}{l}\text { For each study, present characteristics for which data were extracted (e.g., study } \\
\text { size, PICOS, follow-up period) and provide the citations. }\end{array}$ & Yes (Table 1) \\
\hline Risk of bias within studies & 19 & $\begin{array}{l}\text { Present data on risk of bias of each study and, if available, any outcome level } \\
\text { assessment (see item 12). }\end{array}$ & Not available \\
\hline Results of individual studies & 20 & $\begin{array}{l}\text { For all outcomes considered (benefits or harms), present, for each study: (a) } \\
\text { simple summary data for each intervention group (b) effect estimates and } \\
\text { confidence intervals, ideally with a forest plot. }\end{array}$ & Not applicable \\
\hline Synthesis of results & 21 & $\begin{array}{l}\text { Present results of each meta-analysis done, including confidence intervals and } \\
\text { measures of consistency. }\end{array}$ & Not applicable \\
\hline
\end{tabular}




\begin{tabular}{llll}
\hline Section/topic & $\#$ & Checklist item & Reported (Yes/No) \\
\hline Risk of bias across studies & 22 & Present results of any assessment of risk of bias across studies (see Item 15). & Yes \\
Additional analysis & 23 & $\begin{array}{c}\text { Give results of additional analyses, if done (e.g., sensitivity or subgroup analy- } \\
\text { ses, meta-regression [see Item 16]). }\end{array}$ & Not available
\end{tabular}

Discussion

Summary of evidence $\quad 24 \quad$ Summarize the main findings including the strength of evidence for each main Yes (Table 1) outcome; consider their relevance to key groups (e.g., healthcare providers, users, and policy makers).

$25 \quad \begin{aligned} & \text { Discuss limitations at study and outcome level (e.g., risk of bias), and at } \\ & \text { review-level (e.g., incomplete retrieval of identified research, reporting bias). }\end{aligned}$

Conclusions 26 Provide a general interpretation of the results in the context of other evidence, Yes and implications for future research.

Funding

Funding

27 Describe sources of funding for the systematic review and other support (e.g.,

supply of data); role of funders for the systematic review.

Moher et al. [71]. For more information, visit: www.prisma-statement.org.

\section{References}

1. Joint United Nations Programme on HIV/AIDS (UNAIDS). The Gap report. 2014: Geneva,Switzerlan. UNAIDS/JC2684.

2. European Center of Disease Prevention and Control (ECDC), HIV Testing: increase uptake and effectiveness in the European Union. 2010: Solna, Sweden.

3. World Health Organization (WHO), Consolidated guidelines on HIV testing services 2015. July, 2015:Geneva, Switzerlan.

4. Joint United Nations Programme on HIV/AIDS (UNAIDS). 90-90-90 An ambitious treatment to help end the AIDS epidemic. 2014: Geneva, Switzerlan.

5. Aral OS, Blanchard FJ. Phase specific approaches to the epidemiology and prevention of sexually transmitted diseases. Sex Transm Infect. 2002;78(1):1-12.

6. Platt L, Grenfell P, Fletcher A, Sorhaindo A, Jolley E, Rhodes T, Bonell C. Systematic review examining differences in HIV, sexually transmitted infections and health-related harms between migrant and non-migrant female sex workers. Sex Transm Infect. 2013;89:311-9.

7. Platt L, Jolley E, Rhodes T, Hope V, Latypov A, Reynolds L, Wilson D. Factors mediating HIV risk among female sex workers in Europe: a systematic review and ecological analysis. BMJ Open. 2013;3:e02836.

8. Baral S, Beyrer C, Muessig K, Poteat T, Wirtz LA, Decker RM, Sherman GS, Kerrigan D. Burden of HIV among female sex workers in low-income and middle-income countries: a systematic review and meta-analysis. Lancet Infect Dis. 2012;12:538-49.

9. Shahmanesh M, Patel V, Mabey D, Cowan F. Effectiveness of interventions for the prevention of HIV and other sexually transmitted infections in female sex workers in resource poor setting: a systematic review. Trop Med Int Health. 2008;13(5):59-679.

10. Wariki W.M., Ota E., Mori R., Koyanagi A., Hori N., Shibuya K., Behavioral interventions to reduce the transmission of HIV infection among sex workers and their clients in low- and middleincome countries (Review). TheCochraneCollaboration and published in TheCochrane Library, 2012(2).

11. Andrea L, Wirtz CP, Beyrer C, Baral S, Decker RM, Sherman GS. Epidemic impacts of a community empowerment intervention for HIV prevention among female sex workers in generalized and concentrated epidemics. PLoS ONE. 2014;9(2):e88047.

12. Kerrigan LD, Stromdahl S, Fonner AV, Kennedy EC. Community empowerment among female sex workers is an effective HIV prevention intervention: a systematic review of the peer-reviewed evidence from low- and middle-income countries. AIDS Behav. 2013;17:1926-40.

13. Suthar AB, et al. Towards universal voluntary HIV testing and counselling: a systematic review and meta-analysis of communitybased approaches. PLoS Med. 2013;10(8):e1001496.

14. Deblonde J., De Koker P., Hamers F. F., Fontaine J., Luchters S., Temmerman M., Barriers to HIV testing in Europe: a systematic review. 2010.

15. Spencer L., Ritchie J., Jane Lewis J., Dillon L., Quality in Qualitative Evaluation: A framework for assessing research evidence, in National Centre for Social Research. 2003.

16. Downs HS, Black N. The feasibility of creating a checklist for the assessment of the methodological quality both of randomised and non-randomised studies of health care interventions. J Epidemiol Community Health. 1997;52:377-84.

17. Parriault MC, et al. HIV-testing among female sex workers on the border between Brazil and French Guiana: the need for targeted interventions. Cadernos de Saude Publica. 2015;31(8):1615-22.

18. Dandona R, et al. HIV testing among female sex workers in Andhra Pradesh, India. AIDS. 2005;19(17):2033-6.

19. Wang Y, et al. Reported willingness and associated factors related to utilization of voluntary counseling and testing services by female sex workers in Shandong Province, China. Biomed Environ Sci. 2010;23(6):466-72.

20. Wang Y, et al. Factors associated with utilization of a free HIV VCT clinic by female sex workers in Jinan City, North China. AIDS Behav. 2011;15(4):702-10.

21. Wilson DP, et al. Sex workers can be screened too often: a costeffectiveness analysis in Victoria, Australia. Sex Transm Infect. 2010;86(2):117-25.

22. Blanchard FJ, Aral OS. Emergent properties and structural patterns in sexually transmitted infection and HIV research. Sex Transm Infect. 2010;86(3):4-9.

23. Xu J, et al. Factors associated with HIV testing history and HIVtest result follow-up among female sex workers in two cities in Yunnan, China. Sex Trans Dis. 2011;38(2):89-95.

24. King EJ, Maman S. Structural barriers to receiving health care services for female sex workers in Russia. Qual Health Res. 2013;23(8):1079-88.

25. Deering KN, et al. Successes and gaps in uptake of regular, voluntary HIV testing for hidden street- and off-street sex workers in Vancouver, Canada. AIDS Care. 2015;27(4):499-506. 
26. Aho J, et al. High acceptability of HIV voluntary counselling and testing among female sex workers: impact of individual and social factors. HIV Med. 2012;13(3):156-65.

27. Bengtson AM, et al. Levels of alcohol use and history of HIV testing among female sex workers in Mombasa, Kenya. AIDS Care. 2014;26(12):1619-24.

28. Batona $\mathrm{G}$, et al. Understanding the intention to undergo regular HIV testing among female sex workers in Benin: a key issue for entry into HIV care. J Acquir Immune Defic Syndr. 1999;2015(68):S206-12.

29. Dugas M, et al. Outreach strategies for the promotion of HIV testing and care: closing the gap between health services and female sex workers in Benin. J Acquir Immune Defic Syndr. 1999;2015(68):S198-205.

30. Grayman JH, et al. Factors associated with HIV testing, condom use, and sexually transmitted infections among female sex workers in Nha Trang, Vietnam. AIDS Behav. 2005;9(1):41-51.

31. Hong Y, et al. HIV testing behaviors among female sex workers in Southwest China. AIDS Behav. 2012;16(1):44-52.

32. Todd CS, et al. Prevalence and correlates of condom use and HIV testing among female sex workers in Tashkent, Uzbekistan: implications for HIV transmission. AIDS Behav. 2007;11(3):435-42.

33. Tran BX, et al. HIV voluntary testing and perceived risk among female sex workers in the Mekong Delta region of Vietnam. Glob Health Action. 2013;6:20690.

34. King EJ, et al. Motivators and barriers to HIV testing among street-based female sex workers in St. Petersburg, Russia. Global Public Health. 2017;12(7):876-91.

35. Shokoohi M, et al. Correlates of HIV Testing among Female Sex Workers in Iran: findings of a National Bio-Behavioural Surveillance Survey. PLoS ONE. 2016;11(1):e0147587.

36. Sayarifard A, Kolahi A, Hamedani MH. Frequency of performing HIV test and reasons of not-testing among female sex workers. Am J Epidemiol. 2011;173:S197.

37. Deering K, et al. Mapping spatial barriers and facilitators to HIV testing by work environments among sex workers in Vancouver, Canada. J Int AIDS Soc. 2012;15:171-2.

38. Park M, Yi H. HIV prevention support ties determine access to HIV testing among migrant female sex workers in Beijing, China. Am J Epidemiol. 2011;173:S223.

39. Shokoohi M, et al. Remaining gap in HIV testing uptake among female sex workers in Iran. AIDS Behav. 2017;21(8):2401-11.

40. Johnston GL, et al. Associations of HIV testing, sexual risk and access to prevention among female sex workers in the dominican republic. AIDS Behav. 2017;21(8):2362-71.

41. Wang Y, et al. Factors related to female sex workers' Willingness to utilize VCT service: a qualitative study in Jinan City, Northern China. AIDS Behav. 2009;13(5):866-72.

42. Xun H, et al. Factors associated with willingness to accept oral fluid HIV rapid testing among most-at-risk populations in China. PLoS ONE. 2013;8(11):87.

43. Nhurod $\mathrm{P}$, et al. Access to HIV testing for sex workers in Bangkok, Thailand: a high prevalence of HIV among streetbased sex workers. Southeast Asian J Trop Med Public Health. 2010;41(1):153-62.

44. Hong Y, et al. Environmental support and HIV prevention behaviors among female sex workers in China. Sex Transm Dis. 2008;35(7):662-7.

45. Chiao $\mathrm{C}$, et al. Promoting HIV testing and condom use among filipina commercial sex workers: findings from a quasi-experimental intervention study. AIDS Behav. 2009;13(5):892-901.

46. King EJ, et al. The influence of stigma and discrimination on female sex workers' access to HIV services in St. Petersburg, Russia. AIDS Behav. 2013;17(8):2597-603.
47. Ameyan W, et al. Attracting female sex workers to HIV testing and counselling in Ethiopia: a qualitative study with sex workers in Addis Ababa. Afr J AIDS Res. 2015;14(2):137-44.

48. Beattie TS, et al. Personal, interpersonal and structural challenges to accessing HIV testing, treatment and care services among female sex workers, men who have sex with men and transgenders in Karnataka state, South India. J Epidemiol Commun Health. 2012;66:42-8.

49. Chanda MM, et al. Barriers and facilitators to HIV testing among Zambian female sex workers in three transit hubs. AIDS Pat Care Stds. 2017;31(7):290-6.

50. Ngo AD, et al. Health-seeking behaviour for sexually transmitted infections and HIV testing among female sex workers in Vietnam. AIDS Care. 2007;19(7):878-87.

51. Wanyenze RK, et al. "When they know that you are a sex worker, you will be the last person to be treated": perceptions and experiences of female sex workers in accessing HIV services in Uganda. BMC Int Health Human Rights. 2017;17(1):11.

52. Scorgie F, et al. 'We are despised in the hospitals': sex workers' experiences of accessing health care in four African countries. Culture Health Sex. 2013;15(4):450-65.

53. Simonovikj SH, Tosheva M. Model of human rights protection of sex workers exposed to forced HIV/STI testing through combination of court litigation and psycho-social support. J Int AIDS Soc. 2012;15:223.

54. Burke VM, et al. HIV self-testing values and preferences among sex workers, fishermen, and mainland community members in Rakai, Uganda: a qualitative study. PLoS ONE. 2017;12(8):e0183280.

55. Shannon K, Goldenberga MS, Deeringa NK, Steffanie A, Strathdee S, et al. HIV infection among female sex workers in concentrated and high prevalence epidemics: why a structural determinants framework is needed. Curr Opin HIV AIDS. 2014;9(2):174-82.

56. Shannon K., Strathdee A. S., Goldenberg M. S., Duff P., Mwangi P., Rusakova M., Reza-Paul S., Lau J., Deering K., Pickles R. M., Boily M. C., Goldenberg S. M., Deering K. N., Strathdee S. A., Global epidemiology of HIV among female sex workers: infl uence of structural determinants. Lancet HIV and sex workers Series, 2014.

57. World Health Organization (WHO), Delivering HIV test results and messages for re-testing and counselling in adults. 2010: Geneva, Switzerlan.

58. Sarah J, Blondell BK, Mark P, Durham JG. Barriers and facilitators to HIV testing in migrants in high-income countries: a systematic review. AIDS Behav. 2015;21:2012-24.

59. Alvarez-del Arco D, Monge S, Azcoaga A, Rio I, Hernando V, Gonzalez C, Alejos B, Caro MA, Perez-Cachafeiro S, RamirezRubio O, Bolumar F, Noori T, Del Amo J. HIV testing and counselling for migrant populations living in high-income countries: a systematic review. Eur J Pub Health. 2012;23(6):1039-45.

60. Owens GM. Gender differences in health care expenditures, resource utilization, and quality of care. J Manag Care Phar. 2008;4(3):2-6.

61. World Health Organization, W., Global update on the health sector response to HIV, 2014. 2014.

62. Barrington C, Kerrigan D. Debe cuidarse en la calle: Normative influences on condom use among the steady male partners of female sex workers in the Dominican Republic. Cult Health Sex. 2015;16:273-87.

63. Deering NK, Bhattacharjee P, Bradley J, Moses SS, Shannon K, Shaw YS, Washington R, Lowndes MC, Boily MC, Ramesh MB, Rajaram S, Gurav K, Alary M. Condom use within non-commercial partnerships of female sex workers in southern India. BMC Public Health. 2011;11(6):S11. 
64. Kerrigana D, Ellenb M. Environmental-structural factors significantly associated with consistent condom use among female sex workers in the Dominican Republic. AIDS. 2003;17:415-23.

65. Factbook, 100 Countries and Their Prostitution Policies. 2015 Last updated on: 4/1/2015; Available from: http://prostituti on.procon.org/view.resource.php?resourceID $=000772$.

66. Stangl LA, Lloyd JK, Brady ML, Hollandand EC, Baral S. A systematic review of interventions to reduce HIV-related stigma and discrimination from 2002 to 2013: how far have we come? J Int AIDS Soc. 2013;16(2):S32.

67. World Health Organization (WHO), Guideline on HIV disclouser conselling for children up to 12 years of age. 2011, Geneva, Switzerlan.
68. Grossman I. C., Stangl L. A., Global action to reduce HIV stigma and discrimination. Journal of the International AIDS Society 2013.16(2).

69. Joint United Nations Programme on HIV/AIDS (UNAIDS), Policy brief: Criminalisation of HIV transmission. 2008: Geneva, Switzerlan.

70. Global Network of People Living with HIV, The global criminalisation scan report. 2010.

71. Moher D, Liberati A, Tetzlaff J, Altman DG. Preferred reporting items for systematic reviews and meta-analyses: the PRISMA statement. PLoS Med. 2009;6(6):e1000097. https://doi. org/10.1371/journal.pmed1000097. 